\title{
M. Moradi-Jalal, S. Arianfar, B. Karney, A. Colombo. Water Resource Management for Iran's Persepolis Complex
}

\section{Sébastien Gondet}

\section{(2) OpenEdition}

1 Journals

\section{Édition électronique}

URL : http://journals.openedition.org/abstractairanica/40381

DOI : 10.4000/abstractairanica.40381

ISSN : 1961-960X

Éditeur :

CNRS (UMR 7528 Mondes iraniens et indiens), Éditions de l'IFRI

\section{Édition imprimée}

Date de publication : 1 décembre 2013

ISSN : 0240-8910

Référence électronique

Sébastien Gondet, « M. Moradi-Jalal, S. Arianfar, B. Karney, A. Colombo. Water Resource Management for Iran's Persepolis Complex », Abstracta Iranica [En ligne], Volume 32-33 | 2013, document 103, mis en ligne le 01 juillet 2016, consulté le 05 octobre 2020. URL : http://journals.openedition.org/ abstractairanica/40381 ; DOI : https://doi.org/10.4000/abstractairanica.40381

Ce document a été généré automatiquement le 5 octobre 2020.

Tous droits réservés 


\title{
M. Moradi-Jalal, S. Arianfar, B. Karney, A. Colombo. Water Resource Management for Iran's Persepolis Complex
}

\author{
Sébastien Gondet
}

\section{RÉFÉRENCE}

M. Moradi-Jalal, S. Arianfar, B. Karney, A. Colombo. « Water Resource Management for Iran's Persepolis Complex », in : L. W. Mays, ed., Ancient Water Technologies. DordrechtHeidelberg - London - New York, Springer, 2010, p. 87-102.

1 Cet article traite de la question, encore peu abordée, de la gestion de l'eau à l'époque achéménide, en se concentrant sur l'approvisionnement de la terrasse de Persépolis. D'après les AA., parallèlement à la récupération de l'eau de pluie qu'indique une grande citerne à l'est de la terrasse, Persépolis serait en partie alimenté par un canal de plusieurs kilomètres, longeant les pentes au nord du site. Des sections rupestres de ce canal sont connues par les prospections de W. Kleiss dans la région. Les AA. supposent que le canal était alimenté depuis un complexe de sources karstiques situées à $13 \mathrm{~km}$ au nord-est de Persépolis, à proximité du village de Seidan. Les mesures de débit présentées montrent que ces sources fournissent un volume d'eau important, susceptible d'avoir alimenté le canal. A Persépolis, l'eau serait drainée par le réseau de canalisations souterraines de la terrasse fouillé par E. F. Schmidt. Cette hypothèse se fonde sur l'ampleur du réseau jugé surdimensionné par rapport aux volumes d'eau de pluie à évacuer, même en cas de fortes précipitations, calculés à partir de données météorologiques récentes. Ce réseau aurait aussi servi à drainer l'eau du canal et à assurer une alimentation pérenne en eau courante. Des travaux, encore inédits, d'une mission irano-française, ont permis de calculer le profil du canal : les mesures ont mis en évidence qu'il n'atteignait pas le niveau de la terrasse, mais alimentait les terrains 
situés en contrebas à l'ouest. Dans la présentation du contexte historique et archéologique, cet article fourmille d'erreurs.

\section{AUTEURS}

\section{SÉBASTIEN GONDET}

Université Lyon 2 